This is a post-peer-review, pre-copy edited version of an article published in The International Review of Victimology. The definitive publisher-authenticated version [Funk, L., Spencer, D., \& Herron, R. (2020). Making sense of workplace violence and victimization in health care work: the emotional labour of 'not taking it personally.' International Review of Victimology. Advance online publication at: https://journals.sagepub.com/doi/10.1177/0269758020953760 ] is available online at: https://doi.org/10.1177/0269758020953760

\title{
Making sense of violence and victimization in health care work: the emotional labour of 'not taking it personally'
}

Funk, L.M., ${ }_{1}$ Spencer, D.,2 and Herron, R.3

*Corresponding Author

1Laura Megan Funk, Associate Professor, Department of Sociology and Criminology, University of Manitoba. 307-183 Dafoe Road, Isbister Building, University of Manitoba, Winnipeg, Manitoba, Canada. R3T 2N2. Phone: 204-474-6678 Laura.Funk@umanitoba.ca

${ }_{2}$ Dale Spencer, Associate Professor, Department of Law and Legal Studies, Carleton University, Ottawa, Canada.

3Rachel Herron, Associate Professor, Department of Geography, Brandon University, Brandon, Manitoba, Canada.

\section{Acknowledgements}

This research was funded by a grant from Riverview Health Centre. We appreciate the contributions of all study participants, as well as Ms. Linda Hilash, Ms. Sheryl Peters, Ms. Catherine Davey and Mr. Austin Bernier for their research support. 
This is a post-peer-review, pre-copy edited version of an article published in The International Review of Victimology. The definitive publisher-authenticated version [Funk, L., Spencer, D., \& Herron, R. (2020). Making sense of workplace violence and victimization in health care work: the emotional labour of 'not taking it personally.' International Review of Victimology. Advance online publication at: https://journals.sagepub.com/doi/10.1177/0269758020953760 ] is available online at: https://doi.org/10.1177/0269758020953760

\title{
Making sense of violence and victimization in health care work: the emotional labour of 'not taking it personally'
}

\begin{abstract}
Despite significant impacts on employee health, workplace violence tends to minimized and normalized by service workers and by organizations, with employees implicitly held culpable for causing aggression through how they manage interactions. Little is known about how workers accomplish minimization and normalization, or how this process might be entwined with the emotional labour of containing difficult emotions. In this paper an emotional labour lens is joined with a social phenomenological approach to analyze in-depth interviews with twenty-six employees of one multi-unit health care facility in Western Canada. The purpose was to examine health care workers' emotional and interpretive responses to aggression from patients and families. To act deeply and maintain their moral identities, workers contained fear through minimizing and normalizing aggression and contained frustration through acknowledging mitigating circumstances. This involved constructing themselves as victims of misdirected emotions, and patients and families as victims of aging, caregiving, disability, dementia, and/or dying processes. Emotional labour supports organizational interests in ensuring smooth workflows and promoting patient satisfaction and well-being. It involves ambivalence and contradiction and can reproduce discourses detrimental both to workers and to resident care.
\end{abstract}

KEYWORDS: Canada; emotional labour; interpretive methodology; residential care work; workplace violence. 
This is a post-peer-review, pre-copy edited version of an article published in The International Review of Victimology. The definitive publisher-authenticated version [Funk, L., Spencer, D., \& Herron, R. (2020). Making sense of workplace violence and victimization in health care work: the emotional labour of 'not taking it personally.' International Review of Victimology. Advance online publication at: https://journals.sagepub.com/doi/10.1177/0269758020953760 ] is available online at: https://doi.org/10.1177/0269758020953760

Existing international scholarship has identified workplace violence as an issue in a wide variety of occupational fields, such as call centre work (Grandey et al., 2004), employment centres (Bishop et al., 2005), security and policing (Button and Park, 2009; Martin, 1999; Schaible and Gecas, 2010), and airline/railway industries (Boyd, 2002). Workers in healthcare settings are particularly at risk (Standing Committee on Health, 2019), including nurses and ambulance staff (di Martino 2002; Crilly, Chaboyer and Creedy 2004; Gacki-Smith et al., 2009), hospice workers (Gunaratnam 2001) and care aides (Geiger-Brown et al., 2007; Kelly 2017), whom often disproportionately represent both gendered and racialized populations. In Canada's long-term care sector, violence against care aides, including forms of racism and sexism, has been identified as a particular problem, and connected to broader systemic and organizational forces in that sector (Banerjee et al., 2012; Braedley et al., 2018; Brophy, Keith and Hurley 2019).

Above and beyond the difficult emotions and stress arising from violent encounters at work, the process by which workers manage and regulate their emotions and emotional displays in these moments can also be problematic, contributing to emotional dissonance, burnout, guilt, depression, detachment, depersonalization, and exhaustion (Geiger-Brown et al., 2007; Mann, 2005; Schaible and Gecas, 2010). Indeed, "the worker can become estranged or alienated from an aspect of self $[\ldots]$ that is used to do the work" (Hochschild, 1983: 7). 
This is a post-peer-review, pre-copy edited version of an article published in The International Review of Victimology. The definitive publisher-authenticated version [Funk, L., Spencer, D., \& Herron, R. (2020). Making sense of workplace violence and victimization in health care work: the emotional labour of 'not taking it personally.' International Review of Victimology. Advance online publication at: https://journals.sagepub.com/doi/10.1177/0269758020953760 ] is available online at: https://doi.org/10.1177/0269758020953760

In the last 30 years researchers have identified a drive by organisations to access, valorize and actively manipulate employees' emotional knowledge and skills, as a dimension of labour power and often as an aspect of 'customer service' (Alvesson, 2004; Korczynski, 2003; Warhurst and Nickson, 2007; Van Dijk, Smith and Cooper, 2011). Front-line employees may be required to "induce or suppress feeling in order to sustain the outward countenance that produces the proper state of mind in others" (Hochschild, 1983: 7). These expectations may be intensifying as corporations seek competitive gain through promoting the adage, "the customer is always right" (Boyd, 2002; Grandey et al., 2004; Yagil, 2008). In situations where clients act aggressively toward workers, this can render workers relatively powerless, and exacerbate structured inequities.

The objective of this article is to apply the concept of emotional labour (Hochschild, 1983) to explore how aggressive acts by patients or their family members are interpreted by nurses and care aides in a residential health care setting. Emotional labour illuminates how organisations can produce vulnerabilities in workers by requiring them to suppress their emotional responses to verbal and physical abuse in interactions with clients or customers (Johnson, 2015). This concept can enhance our understanding of how and why workers respond in particular ways to experiences of violence or aggression. Hochschild (1979; 1983) explains how organisationally prescribed norms about appropriate emotions and their display contribute to self-presentation processes such as surface acting (i.e., regulating emotional display or expression), or deep acting (i.e., modifying emotions themselves). The latter entails, for instance, control of physiological reactions as well as invoking thoughts and ideas associated with specific emotions so as to 
This is a post-peer-review, pre-copy edited version of an article published in The International Review of Victimology. The definitive publisher-authenticated version [Funk, L., Spencer, D., \& Herron, R. (2020). Making sense of workplace violence and victimization in health care work: the emotional labour of 'not taking it personally.' International Review of Victimology. Advance online publication at: https://journals.sagepub.com/doi/10.1177/0269758020953760 ] is available online at: https://doi.org/10.1177/0269758020953760

generate required feelings (Ashforth and Humphrey, 1993; Bhowmick and Mulla, 2016; Thoits, 1990).

Some emotional labour literature psychologizes these processes as a form of emotionfocused coping in response to stressful situations (Grandey et al., 2004; Yagil, 2008), obscuring how emotion regulation is structurally shaped, commodified and intensified (in training, by management, in organizational discourse and policy), and how organisational conditions contribute to the threat of violence experienced by workers (Banerjee et al., 2012; Boyd, 2002; Wharton, 2009). It is the former perspective that allows Grandey and colleagues (2004) to claim that deep acting is beneficial for worker coping (and thus, for well-being), and that it should be actively promoted within organizations.

Although the concept of emotional labour requires attention to workplace and organizational context, this does not negate the possibility of in-depth exploration into the interpretive activities engaged by workers experiencing violence and aggression on the job. These are social constructions through which workers align themselves with dominant feeling and emotional display norms within their workplace (in particular, emotional suppression). Most research on workplace violence applies positivist approaches with less attention to interpretive examinations of the discursive construction by workers and by formal organisations (Bishop et al., 2005). It is surprising that interpretive methodologies are not more extensively engaged in relation to emotional labour and workplace violence, especially since interpretive knowledge could help explain issues such as low reporting of violence (McDonald et al., 2012).

Certain interpretations of workplace violence may dominate in some settings more than others; the nature of these interpretations reflect and further shape workers' abilities to resist 
This is a post-peer-review, pre-copy edited version of an article published in The International Review of Victimology. The definitive publisher-authenticated version [Funk, L., Spencer, D., \& Herron, R. (2020). Making sense of workplace violence and victimization in health care work: the emotional labour of 'not taking it personally.' International Review of Victimology. Advance online publication at: https://journals.sagepub.com/doi/10.1177/0269758020953760 ] is available online at: https://doi.org/10.1177/0269758020953760

emotional labour demands or prevent alienation (Boyd, 2002). Yet across a variety of types of service work, service workers commonly engage individually and collectively (among coworkers) in trivializing, minimizing or normalizing customer and client aggression and violence (Boyd, 2002; Bishop et al., 2005; Martin, 1999; Yagil, 2008). These processes can both reflect and reproduce organisational goals, and serve to constitute workers as culpable for either poor client handling practices, or poor self-control (Bishop et al., 2005). Brockmann (2002) extends this idea by documenting how social care professionals who experience aggression from service user clients may attribute "diminished responsibility" to those individuals.

In response, employees may strive to place responsibility for aggression with the customer as a means to cope in the context of heavy workloads and strained organizational resources; this may be reinforced as coworkers debrief with each other (Bishop et al., 2005). Culpability of the other (and one's own victim status) can be facilitated by the label of violence itself, although as Waddington et al. (2005: 151) warn, this can be a slippery slope: "[that] a recipient of some other person's anger or annoyance finds the experience discomfiting does not necessarily entail that the expression of anger or annoyance is unwarranted".

Furthermore, attributing culpability to aggressive agents becomes complicated or improbable for health care workers providing supports to populations with a range of chronic, degenerative and life-threatening conditions, including dementia. For instance, when persons living with dementia act with aggression, violence is often not even seen as an appropriate term, due to the lack of intent (Dupuis et al., 2012; Gates et al., 1999; McDonald et al., 2015). In health care more broadly, culpabilizing patients or their families may also not align well with caring or professional identities (Li and Arber, 2006). 
This is a post-peer-review, pre-copy edited version of an article published in The International Review of Victimology. The definitive publisher-authenticated version [Funk, L., Spencer, D., \& Herron, R. (2020). Making sense of workplace violence and victimization in health care work: the emotional labour of 'not taking it personally.' International Review of Victimology. Advance online publication at: https://journals.sagepub.com/doi/10.1177/0269758020953760 ] is available online at: https://doi.org/10.1177/0269758020953760

Nonetheless, fuelled by the changing nature of client and patient populations, as well as growing workloads and time constraints, residential health care workers experience a significant amount (and wide range of) aggression and violence (Banerjee et al., 2012; Berdes and Eckert, 2001, 2007; Bostrom et al., 2012; Braedley et al., 2018; Evers et al., 2002; Mercer et al., 1994; Zeller et al., 2009). This can generate feelings of powerlessness, fear of being blamed, and resignation in workers (Åström et al., 2004; Banerjee et al., 2012; Scott et al., 2011).

In health care organisations, emotional labour requirements not only constrain workers' emotional displays in interactions where they experience aggression, but also influence workers' abilities to cope with workplace violence through interpretive processes. Organizational and professional regulation of workers' emotional displays may be increasing in health care fields, given trends towards marketization, rationalization and managerialism (Bone, 2002; Gattuso and Bevan, 2000; Wharton, 2009).

The goals of emotion management in health care may extend beyond organizational goals to instrumental, professional, and therapeutic or philanthropic ones (Sass, 2000; Erickson and Grove, 2008; Bolton and Boyd, 2003). Indeed, Theodosius (2008) classifies nurses' attempts to minimize unacceptable patient behaviour as a form of emotional labour performed for the patient's (not the organization's) benefit. Others have suggested there may be greater worker autonomy and agency to resist emotional imperatives in health care (Lopez, 2006), especially among nurses (Bolton, 2000). Yet feeling rules in health care are sometimes contradictory, with workers balancing tensions between norms from differing sources, such as those related to empathy or professionalism (Bailey et al., 2015; Erickson and Grove, 2008). 
This is a post-peer-review, pre-copy edited version of an article published in The International Review of Victimology. The definitive publisher-authenticated version [Funk, L., Spencer, D., \& Herron, R. (2020). Making sense of workplace violence and victimization in health care work: the emotional labour of 'not taking it personally.' International Review of Victimology. Advance online publication at: https://journals.sagepub.com/doi/10.1177/0269758020953760 ] is available online at: https://doi.org/10.1177/0269758020953760

Keeping in mind the similarities to other forms of service work, the unique features of work in residential health care settings must be considered in any inquiry into emotional labour and interpretations of workplace violence in these settings. Although a tendency to trivialize and normalise workplace aggression in these settings (Åkerström, 2002; Banerjee et al., 2012; Braedley et al., 2018; Dupuis et al., 2012; Herron and Wrathall, 2018) compares to many other types of service work, the specific interpretive processes involved, and connections to emotional labour, need further exploration in these settings. As such, in this article we examine how aggressive acts by patients or their family members are interpreted by residential health care employees. The analytic lens of emotional labour helps conceptualize how employees may be emotionally constrained when responding to workplace aggression, whereas an interpretive approach indicates the active and sometimes conflicted processes involved in this labour.

\section{METHODS}

In-depth qualitative interviews were conducted in 2013-2014 with 26 employees of one large urban health care facility in Canada, which has specialized units for various long-term health needs. In the nature of the services it provides the facility differs from acute care hospitals; in the diversity of resident health conditions and needs, it differs from many typical long-term residential care facilities. The 'public face' of the facility (e.g., website) is that of a patientfocused care organization providing compassionate yet professional services. Emotional or relational aspects of care (e.g. "friend-like" relationships) are not highlighted in these materials.

To understand how workers most involved in hands-on care engage in emotional labour, purposeful maximum variation sampling was used to recruit health care aides (HCAs) and nurses (RNs) from several units: palliative, long-term residential care, complex chronic care, geriatric 
This is a post-peer-review, pre-copy edited version of an article published in The International Review of Victimology. The definitive publisher-authenticated version [Funk, L., Spencer, D., \& Herron, R. (2020). Making sense of workplace violence and victimization in health care work: the emotional labour of 'not taking it personally.' International Review of Victimology. Advance online publication at: https://journals.sagepub.com/doi/10.1177/0269758020953760 ] is available online at: https://doi.org/10.1177/0269758020953760

rehabilitation, and specialized dementia care (See Table 1). Following university and institutional ethics approval, managers distributed letters of invitation to all such employees, and interested participants contacted the first author.

Following an informed consent process, in-person qualitative (semi-structured) interviews conducted by a trained and experienced interviewer were digitally recorded and professionally transcribed verbatim. These were guided by a focus on how participants interpret and respond to emotional needs and processes in patients and their families (and how they manage personal emotions). Workplace violence and aggression emerged inductively as a salient and prolonged topic of discussion in this regard for all but two participants. Probes for elaboration and examples were used to elicit detailed accounts.

An interpretive approach (drawn from social phenomenology, ethnomethodology and discourse analysis: Gubrium and Holstein, 2000) was used to examine how employees collectively use shared ideas about emotions at work to maintain valued identities and act deeply. This methodology directs analytic attention to how employees understand aggression by using localized and/or broader interpretive frameworks of meaning, as well as feeling and display rules. Interview data were viewed as reflecting participants' attempts to align their talk with the expected feeling and display rules dominant within their workplace - i.e., to negotiate a positive identity to oneself and others (Pugh, 2013). Early analysis (conducted by the first author and a research assistant) involved multiple readings of transcripts, sorting data within interviews, identifying and grouping text segments into descriptive topics; and the development of thematic and conceptual codes (and a codebook) based on initial transcripts and using the analytic frame of emotional labour. Following this, we further explored implicit and explicit meanings in talk 
This is a post-peer-review, pre-copy edited version of an article published in The International Review of Victimology. The definitive publisher-authenticated version [Funk, L., Spencer, D., \& Herron, R. (2020). Making sense of workplace violence and victimization in health care work: the emotional labour of 'not taking it personally.' International Review of Victimology. Advance online publication at: https://journals.sagepub.com/doi/10.1177/0269758020953760 ] is available online at: https://doi.org/10.1177/0269758020953760

about patient and family aggression, and continued to refine code categories (with input of the research team) as pieces of data within each code were compared and contrasted within the broader interpretive orientation of this analysis, to generate further insights. To facilitate conceptual and theoretical flexibility and insight generation, the analysis was conducted as we sifted and organized segments of coded text under subheadings in Word software documents.

\section{FINDINGS}

In examining staff descriptions of workplace aggression, we noticed that a wide range of behaviours from patients or family members could have the effect of making workers feel threatened in some way, whether physically, verbally, or through threats to the professional self. Although workers certainly described direct physical attacks, racist comments, and so on, at times they would refer to aggression when speaking about patients that were simply noncompliant or overly demanding. In terms of the emotional effects of these interactions, the former kinds of situations generated feelings of fear and shock, and the latter tended to be associated with feelings of frustration; however, there were plenty of grey areas and the distinctions were often challenging to disentangle.

After a description of the setting and its' organizational emotional labour ideology (for contextualizing the findings), findings pertinent to the analysis of emotional labour are presented in two further sections that explore a) how workers contained fear through minimizing and normalizing aggression and b) how workers contained frustration (and to a lesser extent, fear) through acknowledging mitigating circumstances.

\section{Setting and Emotional Labour Ideology}

In workplace relationships of care, organizationally and professionally promoted feeling 
This is a post-peer-review, pre-copy edited version of an article published in The International Review of Victimology. The definitive publisher-authenticated version [Funk, L., Spencer, D., \& Herron, R. (2020). Making sense of workplace violence and victimization in health care work: the emotional labour of 'not taking it personally.' International Review of Victimology. Advance online publication at: https://journals.sagepub.com/doi/10.1177/0269758020953760 ] is available online at: https://doi.org/10.1177/0269758020953760

rules generally prescribe ignoring verbally abusive comments (and sometimes even physical aggression, despite workplace health and safety policies), and engaging in surface and/or deep acting. This serves an instrumental (and organizational) function insofar as it avoids escalating agitation and conflict, preventing personal injury to either party and facilitating the efficient provision of care without distractions.

The organization in the present study foregrounded personalized, patient-focused care and empowerment in its mission statement and website. Although the care was characterized as compassionate, it was primarily described as professional (e.g., 'competent'; 'courteous'). Friend- and family-like relationships were not actively promoted (Funk, Peters and Roger 2018) and in some cases were even discouraged. Nonetheless, employees were encouraged to subsume their interests to those of patients and families, and several employees felt unsupported by management when families made formal complaints. For instance, a female HCA working in chronic care (R23) noted: "the worst thing, working with families, is it's like 'the customer is always right." A dementia care HCA (R10) also noted that her previous manager:

...didn't stick up for the staff. If family members had a problem he would blame us.

Our new manager now will stick up for us and say we follow certain guidelines. It's nice to have that backbone.

Some unit managers actively promoted emotional labour through communicating explicitly or implicitly that the patient or family is morally justified when conflicts arose with workers; this approach added to employee fear and to the imperative of emotional self-control in interactions with patients and families.

Emotional control was also promoted as an important component of professionalism on the 
This is a post-peer-review, pre-copy edited version of an article published in The International Review of Victimology. The definitive publisher-authenticated version [Funk, L., Spencer, D., \& Herron, R. (2020). Making sense of workplace violence and victimization in health care work: the emotional labour of 'not taking it personally.' International Review of Victimology. Advance online publication at: https://journals.sagepub.com/doi/10.1177/0269758020953760 ] is available online at: https://doi.org/10.1177/0269758020953760

units (i.e., prescriptive feeling rule). For example, a female HCA (chronic care, R16) explained, “we're told not to, even if we get angry or frustrated with it, we're not supposed to lash back at them. We're supposed to still stay professional." This can include controlling physiological reactions to situations involving fear and/or frustration. One male HCA (chronic care, R21) emphasized to colleagues the importance of professional responses to aggression; he even suggested that aides who asked to be excused from working with verbally abusive patients were exploiting a practice 'loophole' which increased the workload for other aides.

The account of one female HCA (chronic care, R28), who felt quite unsupported by both management and her union, indicated how emotional labour demands might backfire. She repeatedly criticized what she perceived as a 'no consequences' management approach to problematic patient actions (including but not limited to verbal or physical aggression), and believed her manager had a 'one-sided' approach to the official 'no tolerance of aggression' policy in practice, only applying it to staff misbehaviour.

Even with more supportive managers, participants generally perceived few viable options to respond to aggression. Considered together, facility promotional material (i.e., patient-centred narratives), interactions with management, professional training, and normative pressures between coworkers encouraged emotional suppression - especially of frustration. The imperative to suppress fear was less easy to identify at the organizational level, although workers appeared to strive to present themselves as 'coping well' despite the threat of workplace violence. This will be addressed in the next section.

\section{Minimizing and Normalizing: Workers 'Coping Well' with the Threat of Violence}


This is a post-peer-review, pre-copy edited version of an article published in The International Review of Victimology. The definitive publisher-authenticated version [Funk, L., Spencer, D., \& Herron, R. (2020). Making sense of workplace violence and victimization in health care work: the emotional labour of 'not taking it personally.' International Review of Victimology. Advance online publication at: https://journals.sagepub.com/doi/10.1177/0269758020953760 ] is available online at: https://doi.org/10.1177/0269758020953760

Workers' tendencies to minimize and normalize workplace violence, a pattern confirmed in the present study, can be viewed through the lens of emotional labour. Through their talk, they attempted to present themselves as fearless in the interview interaction as a means to convince themselves (deep acting) and others (surface acting) that they were not bothered by workplace violence and aggression, thereby minimizing the threat and managing feelings such as fear and shock. Workers used particular strategies to ascribe violence with a sense of ordinariness; however, the data illuminated the struggle and resistance involved in this process. Indeed, fear often seeped out in their talk.

Examples of minimizing violence (particularly common among employees on non-palliative units) included participant comments about sexually inappropriate remarks from patients ("he was just trying to be funny" R5); verbal threats ("she was all just talk"); physical violence ("you get some nice slaps in the face and stuff" R10); name-calling ("of course I don't give a shit" R13), and other verbal abuse ("just don't mind them, they're not physically aggressive anyways" R21). A female RN (chronic care, R17) minimized her fear of one patient who she described as occasionally violent: "it's not entirely threatening because he's not able to actually hurt somebody but he gets really emotionally, I won't say abusive, that's maybe too strong a word, but can throw really nasty [words] at some of the staff." A male RN (dementia care, R11) was similarly careful with his language, saying "I stay away from the word aggressive, but it's more like reactive and responsive behaviour." Avoiding the language of abuse or violence may echo the narratives of dementia advocacy groups that have in recent years fought against labelling or stigmatizing persons with dementia as violent. Such processes may also be linked to more localized organizational and peer pressures, as workers strove present themselves as strong and 
This is a post-peer-review, pre-copy edited version of an article published in The International Review of Victimology. The definitive publisher-authenticated version [Funk, L., Spencer, D., \& Herron, R. (2020). Making sense of workplace violence and victimization in health care work: the emotional labour of 'not taking it personally.' International Review of Victimology. Advance online publication at: https://journals.sagepub.com/doi/10.1177/0269758020953760 ] is available online at: https://doi.org/10.1177/0269758020953760

'coping well' with workplace violence; however, those who do not cope well were judged negatively by coworkers and management.

Normalizing aggression as a common and expected experience was also a frequent response among workers, positioned as a learned skill or orientation acquired over time. Two HCAs on a specialized dementia care unit, for instance, both believed that physical aggression from residents (which often occurs as resistance to providing personal care) over time starts to seem more ordinary or normal, and thus easier to cope with personally. One (R12) positioned this as the inevitable outcome of population aging and dementia: "these things happen every day in every facility, regardless if they're a specialty unit, because dementia or those kinds of behaviours are just spread out through the system everywhere and will be more so in the future."

Although some participants expressed a resigned acceptance to personal harm as a normal part of the job, not all workers were silent about the emotional effects of aggressive actions from patients or families. For instance, a female HCA (geriatric rehabilitation, R27) characterized verbal and physical aggression ("being rude to you, call you names, and hit you or spit") as very difficult, in part because she feels personally rejected. She provided an example:

[Patient] got really aggressive when we [were] changing him and he hit me. So my glasses fly, and my eyes were blue after the next day, and he broke my glasses, and sometimes they kick you so hard. It's funny but you go home and then next day you go out somewhere, my husband says 'That wasn't me' (Laughs) 'That wasn't me. I didn't hit her.' Sometimes we're laughing, but it does happen, or they kick you or things, lots of bruises.

Though her laughter suggests an attempt at brushing off the emotional impact of the violence, 
This is a post-peer-review, pre-copy edited version of an article published in The International Review of Victimology. The definitive publisher-authenticated version [Funk, L., Spencer, D., \& Herron, R. (2020). Making sense of workplace violence and victimization in health care work: the emotional labour of 'not taking it personally.' International Review of Victimology. Advance online publication at: https://journals.sagepub.com/doi/10.1177/0269758020953760 ] is available online at: https://doi.org/10.1177/0269758020953760

feelings of distress, sadness, and fear dominated the rest of this participant's interview, and she told us that the most difficult aspect of her job was the aggression she experienced.

Similarly, another HCA (R10) explained: "at first I kind of laughed if off because you have to...but now it kind of gets overwhelming after a while." The latter participant struggled to manage her shock at daily experiences of physical violence (e.g., "It's not like we're police or something. We work in a hospital and we get beat up").

Overall, the data demonstrates that normalization and minimization, as forms of deep acting, are not necessarily straightforward or necessarily helpful or effective processes for suppressing feelings such as shock and fear in the face of workplace violence. It is possible that deep acting (changing feelings) may not even be possible for some workers, especially those who may not feel supported by management or even feel blamed for violence incidents. For instance, in the health agency - which managed this and other facilities in the area - concerns about patient aggression were addressed by implementing mandatory staff training about how to better approach patients, suggesting the responsibility lies with individual workers rather than management or policy-makers. This was complicated by the fact that aggression (in patients at least) often lacked intent, and organizational ideologies prioritized the needs of patients and families above those of workers. This is further explicated below, as we explore how participants laboured to suppress frustration when faced with behaviours they interpreted as threatening.

\section{Acknowledging Mitigating Circumstances: A Focus on Patient and Family Coping}

Trying to suppress frustration requires deep acting, and in this regard, the analysis identified one dominant overarching interpretive framework that located aggression in patients' and families' poor coping with difficult (and mitigating) circumstances. As well as being used to 
This is a post-peer-review, pre-copy edited version of an article published in The International Review of Victimology. The definitive publisher-authenticated version [Funk, L., Spencer, D., \& Herron, R. (2020). Making sense of workplace violence and victimization in health care work: the emotional labour of 'not taking it personally.' International Review of Victimology. Advance online publication at: https://journals.sagepub.com/doi/10.1177/0269758020953760 ] is available online at: https://doi.org/10.1177/0269758020953760

suppress frustration, this framework was also invoked to suppress fear, though was perhaps less effective for this purpose. Focusing on mitigating patient and family circumstances may have helped workers produce empathetic or even pitying responses, and helped them to not 'take it personally.' This labour, which was strongly encouraged by coworkers and management, helped employees alter their feelings in relation to others and thereby provide a more authentic performance, as required by the organization and in some cases by unit and professional norms.

This phenomenon was evident across differing units and patient populations, and/or family members who acted in ways perceived as aggressive were characterized as coping poorly with (and perhaps in denial of) patient deterioration. Dying, physical dependency, institutionalization, caregiving, dementia and the like were framed as mitigating circumstances absolving patients and families (as victims) of responsibility for their actions and could promote empathetic employee responses. Many participants actively learned (and/or taught) these interpretations through interactions with coworkers and management; few provided details of where or how they learned them.

Dying and Bereavement. Among dying patients and their families, unresolved or unacknowledged grief, denial, and emotional distress were believed to manifest as anger expressed through verbal abuse or aggression towards staff, characterised as venting, scapegoating or passive-aggression. A female HCA (palliative care, R5) described her struggle suppressing her emotional reactions to verbal abuse and threats from patients and families by invoking a similar frame: 
This is a post-peer-review, pre-copy edited version of an article published in The International Review of Victimology. The definitive publisher-authenticated version [Funk, L., Spencer, D., \& Herron, R. (2020). Making sense of workplace violence and victimization in health care work: the emotional labour of 'not taking it personally.' International Review of Victimology. Advance online publication at: https://journals.sagepub.com/doi/10.1177/0269758020953760 ] is available online at: https://doi.org/10.1177/0269758020953760

They're going through this and they're tired, they're irritable and their loved one is passing away. You have to be able to push through that, to understand from their perspective. It's hard though sometimes, like it's very difficult.

A palliative care nurse (R26) similarly applied a denial frame to explain family "nastiness": Sometimes when the families aren't accepting what's happening or having a hard time coping or they're very angry, they really lash out at us... we've also noticed that sometimes when families are there a lot and they're angry and not coping well, they pick out the little things like... 'oh his bed sheets are all wrinkled' and they get really, really angry with that. And they'll go to the manager. They'll complain to every single staff member...

A female palliative care nurse (R9) described mentoring younger staff by helping them invoke interpretive frames about family members' emotions (anger in particular). Although the impending death of a loved one was constructed as an important mitigating factor, her frames also drew on assumptions about past family histories and coping skills:

You remove that anger from you and realize that it's not at you. It's the reason that their [family member] is dying and they may have had a really broken family and the only way they've dealt with emotions is by anger and yelling and at the end it comes out like that too.

Anger towards care staff was understood as reflecting family members' failure to cope successfully with the impending death, consequentially 'unleashing' buried anger (see also Funk, Peters and Roger 2018). 
This is a post-peer-review, pre-copy edited version of an article published in The International Review of Victimology. The definitive publisher-authenticated version [Funk, L., Spencer, D., \& Herron, R. (2020). Making sense of workplace violence and victimization in health care work: the emotional labour of 'not taking it personally.' International Review of Victimology. Advance online publication at: https://journals.sagepub.com/doi/10.1177/0269758020953760 ] is available online at: https://doi.org/10.1177/0269758020953760

Declining function/increasing dependency. When working on units that were home to patients with high physical needs, employees also invoked patient and family coping as the problem. One male HCA (chronic care, R13) explained why patients with motor neuron diseases and paralysis become angry with workers, citing denial:

Because they can't talk; they think you should understand what I'm saying and so I'm gonna say it exactly the same way until you get it. I'm not gonna try and adapt the way I'm communicating because you should just understand because I'm not getting worse. I'm not getting harder to understand...I'm not losing more function.

That is what's going on for them.

This interpretation was also used as workers sought to manage their frustrations with less overtly threatening actions (that might be identified as difficult, non-compliant, or annoying). For instance, a female $\mathrm{RN}$ on the same unit (R17) used a coping frame to explain why families repeatedly complain ("you can see the family is struggling to accept what is [happening with the resident]") and a male HCA (R13) invoked it to explain (and empathize with) non-compliance with efficient care methods by patients with severe physical disability ("which is how I would be. I would be a complete lunatic. If I couldn't scratch my nose, just shoot me"). He also expressed ambivalence about, however: "it's hard to focus on the fact that they're resistant to it for emotional reasons...you're thinking okay let's just get on with it. (Claps his hands) Stop the silliness."

This same HCA connected patient aggression (e.g., name-calling) and demanding behaviour to emotional difficulties with being dependent on others for care: "they think you're paid to be here and do this. That's probably easier for them, not to feel like they're totally 
This is a post-peer-review, pre-copy edited version of an article published in The International Review of Victimology. The definitive publisher-authenticated version [Funk, L., Spencer, D., \& Herron, R. (2020). Making sense of workplace violence and victimization in health care work: the emotional labour of 'not taking it personally.' International Review of Victimology. Advance online publication at: https://journals.sagepub.com/doi/10.1177/0269758020953760 ] is available online at: https://doi.org/10.1177/0269758020953760

beholden to someone who may be very generous in doing all of those things. So they can be a little rude and sometimes they can be way over the top."

Institutionalization. Long term patients or residents were also generally viewed as having troubles not only with dependency, but other challenges associated with institutionalization. At least in the initial stages, this is viewed as a normal, expected reaction upon entry. A female RN (R15) described a newly admitted resident with dementia who was very agitated and disoriented: "it was very different for him so obviously his behaviours escalated and that includes striking out... So before we put all these precautions in place.... or brought the team in to discuss this man's unruly behaviours, we gave him time. We understand that right now he's transitioning. He's very out of sorts and that's normal." In more extreme examples, however, some employees suggested that institutionalization creates personality or behavioural disorders that result in aggression or other frustrating behaviours. The following example illustrates this 'othering' process:

There are residents who are stuck in the bed or wheelchair for the rest of their life. It's understandable that most if not all of them have personality disorders that range from just passive [to] really aggressive residents. We also deal with residents who are impulsive or really aggressive: 'I was calling a minute ago and you're not yet here,' thinking they're the only residents. Again, you cannot blame them, they're isolated in their room, thinking they're the only ones needing the help for the day... on the part of the HCA it's really important to develop that understanding of those behavioural problems (HCA, Chronic Care, R21). 
This is a post-peer-review, pre-copy edited version of an article published in The International Review of Victimology. The definitive publisher-authenticated version [Funk, L., Spencer, D., \& Herron, R. (2020). Making sense of workplace violence and victimization in health care work: the emotional labour of 'not taking it personally.' International Review of Victimology. Advance online publication at: https://journals.sagepub.com/doi/10.1177/0269758020953760 ] is available online at: https://doi.org/10.1177/0269758020953760

A female HCA (chronic care, R28) also tried to connect institutionalization and dependency to psychological problems. Referring to a patient who pushed his call light repeatedly after being put to bed, at first she stated he did it "just to be a pest"; she then attempted an interpretive reframing but appeared unconvinced:

Institutionalized people are different than normal people. Their only control they have is to... order us around and see what they can... I've never been institutionalized, but from what I see they all end up somewhat like that, not all of them, but...

Caregiving and Family Issues. Poor coping was seen as exacerbated among caregivers who might, in addition to witnessing a loved one decline, be grappling with institutionalization guilt, or the baggage of family breakdown. This might occur among family members who have not previously been highly involved or were geographically distant. One female float nurse (R2) characterized a particular kind of family member:

We call it, 'the daughter that blows in from Toronto,' and, 'why did you do this and how come you're doing that?' ...I find if you give them something to do, because maybe it's guilt. 'I didn't look after mom. I'm not the one who's here and now I'm going to make up for it by cracking the whip on that staff.'

In another example, a male nurse (dementia care, R12) described a situation in which a family reacted with anger when restraints were used with a patient, challenging the staff with questions about "why didn't you have more staff to take care of him?" While acknowledging his own inability to respond meaningfully to this question, interpretively he explained their anger by 
This is a post-peer-review, pre-copy edited version of an article published in The International Review of Victimology. The definitive publisher-authenticated version [Funk, L., Spencer, D., \& Herron, R. (2020). Making sense of workplace violence and victimization in health care work: the emotional labour of 'not taking it personally.' International Review of Victimology. Advance online publication at: https://journals.sagepub.com/doi/10.1177/0269758020953760 ] is available online at: https://doi.org/10.1177/0269758020953760

citing their stress, and elaborating that they might be receiving the call at work, or serving as reluctant caregivers (e.g., estranged family or distant neighbours).

Cognitive impairment and dementia. Several employees working in dementia care explained how family members' anxiety and denial about cognitive decline might generate aggressive or confrontational behaviours. For instance, as one female HCA (R10) stated: "we've had some very difficult families where they've had to be told to leave because they don't understand. They think that their wife or whoever ...is going to be the same as they were before and that's not the case so they take it out on us." Aggression here was interpreted as lacking active intention $-\mathrm{a}$ form of displaced emotion inadvertently directed towards employees. One male nurse (dementia care, R11) explained how he and his coworkers used this framing when family members were upset with them about care:

We label the family unfortunately... the family is like this and that, makes us feel better in a way which shouldn't be the case. But after awhile you could really see the whole dynamics, the worst case scenario. It's just more their anger towards not letting go...

Applying these interpretive frames did not ensure employee well-being, and thus are not synonymous with coping. As the HCA cited above (R10) stated: "you leave work and you're still frustrated and you don't understand what went on."

When employees spoke about patients with cognitive impairment, however, there was a slight shift in interpretive emphasis. Workers who cared for persons with dementia were often trained in behavioural modification approaches and de-escalation strategies, and on average, faced situations involving greater of risk of physical harm than on other units. As in most 
This is a post-peer-review, pre-copy edited version of an article published in The International Review of Victimology. The definitive publisher-authenticated version [Funk, L., Spencer, D., \& Herron, R. (2020). Making sense of workplace violence and victimization in health care work: the emotional labour of 'not taking it personally.' International Review of Victimology. Advance online publication at: https://journals.sagepub.com/doi/10.1177/0269758020953760 ] is available online at: https://doi.org/10.1177/0269758020953760

contemporary long-term residential care settings, this unit actively promoted the use of clinical problem-solving skills to ascertain what the patient is trying to communicate and address underlying physiological or other needs.

To maintain emotional control over both frustration and fear, these workers tended to invoke dementia itself (i.e., rather than coping) as a mitigating circumstance (i.e., a more biomedical frame); indeed, it was perhaps easier for these employees to characterize persons with dementia (as opposed to other types of conditions) as victims. Aggression was usually interpreted as a symptom of dementia, albeit one that might be 'triggered' by situational factors or changes. The other nurse noted above (R11) described being confronted by a resident screaming in his face, and explains how he "shuts down" the noise by telling himself, for instance, "it's because of his disease progress or it could be ['sunning down']" because usually a lot of people with dementia get really agitated towards early evening." Just as this participant interpreted screaming as an expected and normal part of the job elsewhere in his talk, he tended to normalize screaming as part and parcel of dementia.

Invoking dementia as a mitigating factor to suppress frustration and/or fear was not necessarily easy or successful. For example, one female HCA (dementia care, R10) expressed considerable distress related to workplace violence (and its unpredictability). Despite trying to understand behaviours associated with dementia, her intense shock at what she encountered at work on a daily basis meant that she struggled with normalization (e.g., insisting the behaviour is not normal). Referring to physically combative or verbally abusive actions, she stated: "even though you know that they don't mean it, it still gets to you after awhile." In a related excerpt, she expressed a desire for further training: 
This is a post-peer-review, pre-copy edited version of an article published in The International Review of Victimology. The definitive publisher-authenticated version [Funk, L., Spencer, D., \& Herron, R. (2020). Making sense of workplace violence and victimization in health care work: the emotional labour of 'not taking it personally.' International Review of Victimology. Advance online publication at: https://journals.sagepub.com/doi/10.1177/0269758020953760 ] is available online at: https://doi.org/10.1177/0269758020953760

Some of them will be smiling as they're hitting you ... I don't think they mean to be smiling. I just don't think it's connecting right; they don't know what they're doing ... They might be seeing a robber or somebody that's trying to attack them or they might not even see a person at all... and I'm not sure what goes through their heads but it would be very interesting to see, to understand. We haven't had a lot of... we have had some information but they really don't... [trails off].

Notably several employees suggested limits to mitigating circumstances and tolerance of abuse, and described taking active attempts, for instance, to insist that patients or families treat them with civility. For instance, one female RN (palliative care, R6) stated: "I absolutely get the anger part but I don't have to be the venting of [their] anger all the time and I don't want to be and I shouldn't have to be." One employee (female HCA, chronic care, R28), who felt extremely unsupported by her manager, framed a range of aggressive, challenging, demanding and resistant actions in terms of bad attitudes and personalities, and demanded that patients and families face consequences: “I'm sorry they're on ventilators, but I didn't put them there so they still have a [responsibility] to treat us just as well as we treat them. It's not fair that they can get away with it...”

On the whole, however, these alternative stances were rare, and instead most participants viewed aggression or threatening behaviour from family members or patients as misdirected or unresolved denial, grief, and anger in response to illness, decline and deterioration, complicated at times by problematic life histories, guilt about dependency (patients), or being unable to care (families). For the most part the circumstances were viewed as mitigating families and patients of responsibility for their actions; instead, the onus was placed on workers themselves to manage 
This is a post-peer-review, pre-copy edited version of an article published in The International Review of Victimology. The definitive publisher-authenticated version [Funk, L., Spencer, D., \& Herron, R. (2020). Making sense of workplace violence and victimization in health care work: the emotional labour of 'not taking it personally.' International Review of Victimology. Advance online publication at: https://journals.sagepub.com/doi/10.1177/0269758020953760 ] is available online at: https://doi.org/10.1177/0269758020953760

interactions with patients and families, as well as manage their own emotions in the face of workplace violence.

\section{DISCUSSION}

Using emotional labour and interpretive inquiry to examine the interpretation of workplace violence in health care reveals how organizations, supported by professional norms, organizational cultures, and broader discourses, collectively promote particular interpretations of and emotional responses to patient/family actions that align with organizational goals (e.g., prioritizing patient/family satisfaction, facilitating efficient workflows). This highly gendered workforce is encouraged to expect aggression as a normal part of their job, not to take it personally, and to act deeply to suppress emotions such as fear and frustration. Lacking support to respond in other more direct ways, to manage fear employees normalize violence as an expected part of the job (rather than a deviant anomaly). In addition, their emotional labour involves invoking dementia, decline, terminal illness and bereavement, physical dependency, and institutionalization as mitigating circumstances triggering difficult emotions in patients and families. In this way, aggressive actions are interpreted as somewhat unhealthy, yet normal coping responses. Braedley et al. (2018: 101) noted a similar phenomenon among residential care workers experiencing racism and sexism: "their underlying perception was that dementia, old age and other illness prevented residents from self-regulating." Empathy, even pity towards the 'agent of violence' are generated through altering "the meaning the participants ascrib[e] to the violent event" (Luck et al., 2008: 1076). Through emotional labour, employees position themselves as scapegoats of patients' or families' displaced anger, lack of control, grief, and so on. 
This is a post-peer-review, pre-copy edited version of an article published in The International Review of Victimology. The definitive publisher-authenticated version [Funk, L., Spencer, D., \& Herron, R. (2020). Making sense of workplace violence and victimization in health care work: the emotional labour of 'not taking it personally.' International Review of Victimology. Advance online publication at: https://journals.sagepub.com/doi/10.1177/0269758020953760 ] is available online at: https://doi.org/10.1177/0269758020953760

Other research has examined how workers employ similar techniques (a focus on patients' 'troubled' emotional reactions) when patients are irritable, demanding or critical (Li and Arber, 2006), to maintain a sensitive, sympathetic and caring self-identity (both a professional norm and highly gendered expectation), and avoid criticizing their patients. Berdes and Eckert (2007) examine how care aides drew on familial metaphors to express affective care despite racial abuse; others suggested this might result in exploitation (Dodson and Zincavage, 2007; Lan, 2002; Pfefferle and Weinberg, 2008). A limitation of the present study was the relative lack of participant diversity, making it difficult to assess the role of racialization; other research suggests emotional labour demands may be amplified among racialized workers (Cottingham et al., 2018).

Ideas about emotional self-control (as professionalism) and philanthropy (empathy, pity) appear to be implicated in deep acting within gendered health care workforces. This might reduce emotional dissonance, but in workplace violence situations, it ultimately serves organizational and managerial interests. By invoking discourses and interpretations that align with their sense of identity as both caring and professional (as well as the organizational culture), participants strive to manage their emotions in situations of aggression. This emotional labour, as well as that involved in normalizing and minimizing violence, is fraught with ambivalence, and contradiction, and is not always successful. Furthermore, these interpretive responses to managing emotions are not always helpful for worker's wellbeing, and deep acting can “deep[en] the individual's subordination to her or his commodification and its alienation" (Brooks, 2009; 534). Even normalization strategies, in the long term, may create a situation in which "one may no longer perceive change as desirable" (Ashforth and Kreiner, 2002). As such, we propose that 
This is a post-peer-review, pre-copy edited version of an article published in The International Review of Victimology. The definitive publisher-authenticated version [Funk, L., Spencer, D., \& Herron, R. (2020). Making sense of workplace violence and victimization in health care work: the emotional labour of 'not taking it personally.' International Review of Victimology. Advance online publication at: https://journals.sagepub.com/doi/10.1177/0269758020953760 ] is available online at: https://doi.org/10.1177/0269758020953760

these are best viewed as social constructions used interpretively to align oneself with dominant ideals and suppress emotions rather than effectively cope with them or change the circumstances in which the threats arise.

These findings reveal another broader social cost to collective processes of emotional labour in workplace violence situations - they reproduce potentially harmful stigmatizing and 'othering' discourses. Participants' emotional labour draws on and perpetuates a belief that those with dementia, disability, terminal illness, etc. are passive victims unable to change their behaviours; family members are characterized as almost incapable of emotional control in difficult circumstances. Although reductionist, biomedical or pathological models help staff members manage their emotions in the immediate situation, in the long term these models become entrenched in practice, and have been identified, for instance, as an obstacle to personcentred care (Doyle and Rubenstein, 2013).

Moreover, when patient and family actions are positioned as unchangeable and unavoidable (e.g., as part of their coping with deterioration and illness), and the roots of aggression are framed as residing in individual circumstances and characteristics, the problem of (and responsibility for) workplace violence is shifted to individual employees and to how they choose to cope and manage the emotional impacts. A psychocentric frame (Rimke and Brock, 2012) diverts attention from deeper roots of violence in the broader environment, such as care staffing deficiencies (Banerjee et al., 2012) or coercive care models, and can limit collective (e.g., union) action on these issues.

Patient-centric approaches to care and (at least in dementia care settings) the rejection of the terminology of violence, though well-intended attempts to combat biomedicalization and 
This is a post-peer-review, pre-copy edited version of an article published in The International Review of Victimology. The definitive publisher-authenticated version [Funk, L., Spencer, D., \& Herron, R. (2020). Making sense of workplace violence and victimization in health care work: the emotional labour of 'not taking it personally.' International Review of Victimology. Advance online publication at: https://journals.sagepub.com/doi/10.1177/0269758020953760 ] is available online at: https://doi.org/10.1177/0269758020953760

dehumanization of patients, can constrain workers' abilities to talk about aggression, and can even represent a form of structural violence (Herron and Rosenberg, 2017; Herron and Wrathall, 2018).

Although similar interpretive tendencies have been noted in the emotion work of unpaid family carers (Herron, Funk and Spencer, 2019; Spencer et al., 2019), paid employees, especially care aides, have few options but to normalize aggression as part of their job; they have few rights in practice (Banerjee et al., 2012); this is exacerbated in the context of heavy workloads and time demands. Our findings should prompt critical reflection on the complex and interlocking explanations for workplace violence; interpretations that can be best understood within the frame of emotional labour, just as emotional labour can benefit from further attention to interpretive (and often gendered) processes among coworkers and within organizational cultures. Understanding the consequences and success or failure of such explanations is critical to the provision of sensitive and sustainable care for care workers, patients, and families. Moreover, future research employing other methodologies (institutional ethnography, dementia care mapping, etc.) could help illuminate how both organizational culture and structural forces linked to the socio-political context of care (e.g., neoliberalism, austerity) reinforce particular interpretations and responses to aggressive actions. At the same time, applied approaches motivated by this knowledge can identify opportunities (e.g., non-forced care models; appropriate staffing to meet workers' and residents' needs) to address the structural roots of violence faced by health care workforces and to re-shape organizational, professional, and public narratives used to explain violence in this setting. 
This is a post-peer-review, pre-copy edited version of an article published in The International Review of Victimology. The definitive publisher-authenticated version [Funk, L., Spencer, D., \& Herron, R. (2020). Making sense of workplace violence and victimization in health care work: the emotional labour of 'not taking it personally.' International Review of Victimology. Advance online publication at: https://journals.sagepub.com/doi/10.1177/0269758020953760 ] is available online at: https://doi.org/10.1177/0269758020953760

\section{References}

Alvesson M (2004) Knowledge Work and Knowledge-Intensive Firms. Oxford University Press: New York.

Ashforth B and Humphrey R (1993) Emotional labour in service roles: The influence of identity. The Academy of Management Review 18(1): 88-115.

Ashforth BE and Kreiner GE (2002) Normalizing emotion in organizations: Making the extraordinary seem ordinary. Human Resource Management Review 12(2): 215-235.

Åström S, Bucht G, Eisemann M, et al. (2002) Incidence of violence towards staff caring for the elderly. Scandinavian Journal of Caring Sciences 16(1): 66-72.

Bailey S, Scales K, Lloyd J, et al. (2015) The emotional labour of health-care assistants in inpatient dementia care. Ageing and Society 35(2): 246-269.

Banerjee A, Daly T, Armstrong P, et al. (2012) Structural violence in long-term, residential care for older people: Comparing Canada and Scandinavia. Social Science and Medicine 74(3): 390-398.

Berdes C and Eckert JM (2001) Race relations and caregiving relationships: A qualitative examination of perspectives from residents and nurse's aides in three nursing homes. Research on Aging 23(1): 109-126. 
This is a post-peer-review, pre-copy edited version of an article published in The International Review of Victimology. The definitive publisher-authenticated version [Funk, L., Spencer, D., \& Herron, R. (2020). Making sense of workplace violence and victimization in health care work: the emotional labour of 'not taking it personally.' International Review of Victimology. Advance online publication at: https://journals.sagepub.com/doi/10.1177/0269758020953760 ] is available online at: https://doi.org/10.1177/0269758020953760

Berdes C and Eckert JM (2007) The language of caring: Nurse's aides' use of family metaphors conveys affective care. Gerontologist 47(3): 47-60.

Bhowmick S and Mulla Z (2016) Emotional labour of policing: Does authenticity play a role? International Journal of Police Science and Management 18(1): 47-60.

Bishop V, Korczynski M and Cohen L (2005) The invisibility of violence: Constructing violence out of the job centre workplace in the UK. Work, Employment and Society 19(3): 583602.

Bolton SC and Boyd C (2003) Trolley dolly or skilled emotion manager? Moving on from as Hochschild's managed heart. Work, Employment and Society 17(2): 289-308.

Bolton SC (2000) Who cares? Offering emotion work as a 'gift' in the nursing labour process. Journal of Advanced Nursing 32(3): 580-586.

Boström AM, Squires JE, Mitchell A, et al. (2012) Workplace aggression experienced by frontline staff in dementia care. Journal of Clinical Nursing 21(9-10): 1453-1465.

Boyd C (2002) Customer violence and employee health and safety. Work, Employment and Society 16(1): 151-169.

Braedley S, Owusu P, Przednowek A, et al. (2018) We're told, 'Suck it up': Long-Term Care Workers' Psychological Health and Safety Ageing International 43(1): 91-109. 
This is a post-peer-review, pre-copy edited version of an article published in The International Review of Victimology. The definitive publisher-authenticated version [Funk, L., Spencer, D., \& Herron, R. (2020). Making sense of workplace violence and victimization in health care work: the emotional labour of 'not taking it personally.' International Review of Victimology. Advance online publication at: https://journals.sagepub.com/doi/10.1177/0269758020953760 ] is available online at: https://doi.org/10.1177/0269758020953760

Brockmann M (2002) New perspectives on violence in social care. Journal of Social Work 2(1): $29-44$.

Brook P (2009) In critical defence of ‘emotional labour': Refuting Bolton's critique of Hochschild's concept. Work, Employment and Society 23(3): 531-548.

Brophy J, Keith M and Hurley M (2019) Breaking point: violence against long-term care staff. New Solutions: A Journal of Environmental and Occupational Health Policy. 29(1): 1035.

Button M and Park H (2009) Security officers and the policing of private space in South Korea: profile, powers and occupational hazards. Policing and Society, 19(3): 247-262.

Cottingham MD, Johnson AH and Erickson RJ (2018) "I can never be too comfortable": Race, gender, and emotion at the hospital bedside. Qualitative Health Research 28(1): 145-158.

Crilly J, Chaboyer W and Creedy D (2004). Violence towards emergency department nurses by patients. Accident and Emergency Nursing 12(2): 67-73.

Di Martino V (2002) Workplace Violence in the Health Sector: Synthesis report. Geneva: World Health Organization.

Doyle PJ and Rubinstein RL (2013) Person-centered dementia care and the cultural matrix of othering. The Gerontologist 54(6): 952-963. 
This is a post-peer-review, pre-copy edited version of an article published in The International Review of Victimology. The definitive publisher-authenticated version [Funk, L., Spencer, D., \& Herron, R. (2020). Making sense of workplace violence and victimization in health care work: the emotional labour of 'not taking it personally.' International Review of Victimology. Advance online publication at: https://journals.sagepub.com/doi/10.1177/0269758020953760 ] is available online at: https://doi.org/10.1177/0269758020953760

Dupuis SL, Wiersma E and Loiselle L (2012) Pathologizing behaviour: Meanings of behaviours in dementia care. Journal of Aging Studies 26(2): 162-173.

Erickson RJ and Grove WJC (2008) Emotional labor and health care. Sociology Compass 2: 704-733.

Evers W, Tomic W and Brouwers A (2002) Aggressive behaviour and burnout among staff of homes for the elderly. International Journal of Mental Health Nursing 11(1): 2-9.

Funk L Peters S and Roger KS (2018). Caring about dying persons and their families: Interpretation, practice and emotional labour. Health and Social Care in the Community 26: 519-26.

Gacki-Smith J, Juarez AM, Boyett, L., et al. (2009) Violence against nurses working in US emergency departments. Journal of Nursing Administration 39(7/8): 340-349.

Gates DM, Fitzwater E and Meyer U (1999) Violence against caregivers in nursing homes: Expected, tolerated, and accepted. Journal of Gerontological Nursing 25(4): 12-22.

Gattuso S and Bevan C (2000). Mother, daughter, patient, nurse: women's emotion work in aged care. Journal of Advanced Nursing, 31(4): 892-899.

Geiger-Brown J, Muntaner C, McPhaul K, Lipscomb J and Trinkoff A (2007) Abuse and violence during home care work as predictors of worker depression. Home Health Care Services Quarterly 26(1): 59-77. 
This is a post-peer-review, pre-copy edited version of an article published in The International Review of Victimology. The definitive publisher-authenticated version [Funk, L., Spencer, D., \& Herron, R. (2020). Making sense of workplace violence and victimization in health care work: the emotional labour of 'not taking it personally.' International Review of Victimology. Advance online publication at: https://journals.sagepub.com/doi/10.1177/0269758020953760 ] is available online at: https://doi.org/10.1177/0269758020953760

Grandey AA, Dickter DN and Sin HP (2004) The customer is not always right: Customer aggression and emotion regulation of service employees. Journal of Organizational Behavior 25(3): 397-418.

Gubrium JF and Holstein JA (2000) Analyzing interpretive practice. In: Denzin NK and Lincoln YS (eds) Sage Handbook of Qualitative Research. Thousand Oaks, CA: Sage, pp.487508.

Gunaratnam Y (2001) "We mustn't judge people ...but": staff dilemmas in dealing with racial harassment amongst hospice service users. Sociology of Health and Illness 23(1): 65-84.

Herron R, Funk L and Spencer D (2019) Responding the "wrong way": The emotion work of caring for a family member with dementia. The Gerontologist 59: 470-78.

Herron RV and Rosenberg M (2017) Responding to aggression and reactive behaviours in the home. Dementia 18(4): 1328-1340.

Herron RV and Wrathall MA (2018) Putting responsive behaviours in place: Examining how formal and informal carers understand the actions of people with dementia. Social Science and Medicine 204: 9-15.

Hochschild AR (1979) Emotion work, feeling rules and social structure. American Journal of Sociology 85(3): 551-575.

Hochschild AR (1983) The Managed Heart: Commercialization of Human Feeling. University of California Press: Berkeley. 
This is a post-peer-review, pre-copy edited version of an article published in The International Review of Victimology. The definitive publisher-authenticated version [Funk, L., Spencer, D., \& Herron, R. (2020). Making sense of workplace violence and victimization in health care work: the emotional labour of 'not taking it personally.' International Review of Victimology. Advance online publication at: https://journals.sagepub.com/doi/10.1177/0269758020953760 ] is available online at: https://doi.org/10.1177/0269758020953760

Johnson EK (2015) The business of care: The moral labour of care workers. Sociology of Health and Illness 37(1): 112-126.

Kelly C (2017) Care and violence through the lens of personal support workers. International Journal of Care and Caring 1(1): 97-113.

Korczynski M (2003) Communities of coping: Collective emotional labour in service work. Organization 10(1): 55-79.

Li S and Arber A (2006) The construction of troubled and credible patients: A study of emotion talk in palliative care settings. Qualitative Health Research 16(1): 27-46.

Lopez SH (2006) Emotional labor and organized emotional care: Conceptualizing nursing home care work. Work and Occupations 33(2): 133-160.

Luck L, Jackson D and Usher K (2008) Innocent or culpable? Meanings that emergency department nurses ascribe to individual acts of violence. Journal of Clinical Nursing 17(8): 1071-1078.

McDonald L, Beaulieu M, Harbison J, et al. (2012) Institutional abuse of older adults: What we know, what we need to know. Journal of Elder Abuse and Neglect 24(2): 138-160.

McDonald L, Sheppard C, Hitzig SL, et al. (2015) Resident-to-resident abuse: A scoping review. Canadian Journal on Aging 34(2): 215-236. 
This is a post-peer-review, pre-copy edited version of an article published in The International Review of Victimology. The definitive publisher-authenticated version [Funk, L., Spencer, D., \& Herron, R. (2020). Making sense of workplace violence and victimization in health care work: the emotional labour of 'not taking it personally.' International Review of Victimology. Advance online publication at: https://journals.sagepub.com/doi/10.1177/0269758020953760 ] is available online at: https://doi.org/10.1177/0269758020953760

Martin SE (1999) Police force or police service? Gender and emotional labor. The Annals of the American Academy of Political and Social Science 561(1): 111-126.

Mercer SO, Heacock P and Beck C (1994) Nurse's aides in nursing homes: Perceptions of training, work loads, racism, and abuse issues. Journal of Gerontological Social Work 21(1-2): 95-112.

Pugh AJ (2013) What good are interviews for thinking about culture? Demystifying interpretive analysis. American Journal of Cultural Sociology 1(1): 42-68.

Rimke H and Brock D (2012) The culture of therapy: Psychocentrism in everyday life. In: Thomas M, Raby R and Brock D (eds) Power and Everyday Practices. Nelson: Toronto, pp.182-202.

Sass JS (2000) Emotional labor as cultural performance: the communication of caregiving in a non-profit nursing home. Western Journal of Communication 64: 330-358.

Schaible LM and Gecas V (2010) The impact of emotional labor and value dissonance on burnout among police officers. Police Quarterly 13(3): 316-341.

Scott A, Ryan A, James I, et al. (2011) Perceptions and implications of violence from care home residents with dementia: A review and commentary. International Journal of Older People Nursing 6(2): 110-122. 
This is a post-peer-review, pre-copy edited version of an article published in The International Review of Victimology. The definitive publisher-authenticated version [Funk, L., Spencer, D., \& Herron, R. (2020). Making sense of workplace violence and victimization in health care work: the emotional labour of 'not taking it personally.' International Review of Victimology. Advance online publication at: https://journals.sagepub.com/doi/10.1177/0269758020953760 ] is available online at: https://doi.org/10.1177/0269758020953760

Spencer D, Funk L, Herron R, Gerbrandt E and Dansereau L (2019) Fear, defensive strategies and caring for cognitively impaired family members. Journal of Gerontological Social Work, 62: 67-85.

Standing Committee on Health (2019).Violence facing health care workers in Canada: Report of the Standing Committee on Health. House of Commons: Ottawa, Canada.

Theodosius C (2008) Emotional Labour in Health Care: The Unmanaged Heart of Nursing. London: Routledge.

Thoits PA (1990) Emotional deviance: Research agendas. In: Kemper TD (ed) Research Agendas in the Sociology of Emotions. SUNY Press: New York, pp.180-203.

Van Dijk PA, Smith LDG and Cooper BK (2011) Are you for real? An evaluation of the relationship between emotional labour and visitor outcomes. Tourism Management 32(1): $39-45$.

Waddington PAJ, Badger D and Bull R (2005) Appraising the inclusive definition of workplace 'violence'. British Journal of Criminology 45: 141-164.

Warhurst C and Nickson D (2007) Employee experience of aesthetic labour in retail and hospitality. Work, Employment and Society 21(1): 103-120.

Wharton AS (2009) The sociology of emotional labor. Annual Review of Sociology 35: 147-165. 
This is a post-peer-review, pre-copy edited version of an article published in The International Review of Victimology. The definitive publisher-authenticated version [Funk, L., Spencer, D., \& Herron, R. (2020). Making sense of workplace violence and victimization in health care work: the emotional labour of 'not taking it personally.' International Review of Victimology. Advance online publication at: https://journals.sagepub.com/doi/10.1177/0269758020953760 ] is available online at: https://doi.org/10.1177/0269758020953760

Yagil D (2008) When the customer is wrong: A review of research on aggression and sexual harassment in service encounters. Aggression and Violent Behavior 13(2): 141-152.

Zeller A, Hahn S, Needham I, et al. (2009) Aggressive Behavior of Nursing Home Residents Toward Caregivers: A Systematic Literature Review. Geriatric Nursing 30(3): 174-187.

Table 1. Sociodemographic Summary of Participants $(n=26)$

\begin{tabular}{|ll|c|}
\hline & & Frequency (\%) \\
\hline \multirow{2}{*}{ Age (years) } & Range & $19-59$ \\
& Average & 44 \\
\hline \multirow{3}{*}{ Gender } & Female & $20(76.9 \%)$ \\
& Male & $6(23.1 \%)$ \\
& Transgender/Nonbinary & 0 \\
\hline \multirow{2}{*}{ Racialization } & Caucasian & $22(84.6 \%)$ \\
& Racialized minority & $4(15.4 \%)$ \\
\hline \multirow{2}{*}{ Position } & Health care aides & $12(46.2 \%)$ \\
& Registered nurses & $14(53.8 \%)$ \\
\hline \multirow{3}{*}{ Units } & Palliative care unit & $12(46.2 \%)$ \\
& Long-term residential & $9(24.6 \%)$ \\
\hline Years of & Other (chronic, & $5(19.23 \%)$ \\
Experience & behavioural, respiratory) & $3-29$ \\
\hline Average hours & Range & 12.1 \\
worked per week & Average & Range \\
\hline
\end{tabular}

